\title{
AS CIDADES E A PARTICIPAÇÃO DEMOCRÁTICA: POSSÍVEIS INOVAÇÕES NA POLÍTICA URBANA BRASILEIRA NO PÓS-1988
}

\section{CITIES AND DEMOCRATIC PARTICIPATION: POSSIBLE INNOVATIONS IN BRAZILIAN URBAN POLITICS POST-1988}

\author{
Danielle Anne Pamplona ${ }^{1}$ \\ Moacir Ribeiro de Carvalho Junior ${ }^{2}$
}

\begin{abstract}
Resumo
O Estatuto da Cidade foi o resultado dos debates surgidos pelo chamado movimento municipalista, do qual participavam associações de moradores, entidades de classes profissionais, e demais órgãos da sociedade civil organizada. Esta lei ampliou, no plano formal, a atuação dos moradores no destino das respectivas cidades, uma vez que estes passaram, no pós 1988, a interferir na elaboração dos planos diretores dos municípios brasileiros. Esse quadro pode ser compreendido como a concretização de diretrizes internacionais que demandam o aprofundamento das possibilidades de participação, como por exemplo, o Pacto Internacional de Direitos Civis e Políticos do qual o Brasil faz parte. Contudo, ao longo dos anos que se seguiram à sua vigência, a participação, conforme os críticos do Estatuto, não passou de uma "ilusão". O presente artigo se propõe a discutir os fundamentos para a demanda da participação, as perspectivas para a participação democrática brasileira na atualidade, assim como algumas possíveis inovações, tudo na seara da política urbana. Para tanto, revisa autores da Ciência Política, Direito e Planejamento Urbano, e as leis correlatas ao tema. A título de considerações, identifica um possível envolvimento da justiça eleitoral na organização de um novo espaço de participação, no qual o instrumento não é o voto, mas a própria voz do cidadão quando o mesmo é qualificado e identificado, no momento de escolher os membros do respectivo conselho da cidade.
\end{abstract}

Palavras-chave: Políticas Públicas; Desenvolvimento Urbano; Estatuto da Cidade; Democracia; Participação.

\begin{abstract}
The CitiesAct, was the outcome of discussions arising at the so-called Counties Movement, which aggregates resident's associations, Professional Class Bodies, and other organs of civil society. This law extended, formally, the residents performance at the destination of their cities, once residents, after 1988, might interfere with the preparation of the Municipalities' Master Plans. This framework can be understood as an embodiment of International Guidelines which require the advancement of participation opportunities, as for example, the International Covenant on Civil and Political Rights to which Brazil is a party. However, over the year's participation is seeing as an 'illusion' for the critics of the Act. The present article aims to discuss the grounds for a demand of participation, the perspectives for democratic participation in Brazil today, and some possible innovations, all referred to urban policy. In order to do so, the text revises authors from fields as Political Science, Law and Urban Planning, and laws related to the theme. The final considerations,
\end{abstract}

\footnotetext{
1 Professora Titular da Pós-Graduação stricto sensu da Pontifícia Universidade Católica do Paraná. Doutora pela Universidade Federal de Santa Catarina. Coordenadora da Clínica de Direitos Humanos da PUC-PR. Email: danielle.pamplona@pucpr.br

2 Doutorando no Programa de Pós-Graduação em Gestão Urbana na Pontifícia Universidade Católica do Paraná. E-mail: moacir.c.jr@gmail.com
} 
the text identifies a possible role of Electoral Judiciary Branch in organizing a new participation space, one in which casting a vote is not the main instrument, but yes, the citizen's voice when he is identified, when he is choosing the City Council members.

Keywords: Public Policies; Urban development; City Act; Democracy; Participation. 


\section{INTRODUÇÃO}

O tema "participação popular" num contexto democrático está relacionado ao estudo do poder. Discutir decisões políticas mediante a inserção de atores oriundos do meio popular é tornar mais complexo o jogo de interesses existentes em dada sociedade, seja pela diversidade de interesses, pelas diferentes capacidades de manifestação, ou pela alta probabilidade de polarização. Tal cenário tende ao conflito, logo, a participação é um processo dinâmico e polêmico.

Dinâmico porque carece de uma estrutura a qual permita atender às constantes mudanças de dada comunidade envolvida, e polêmico porque os interesses dos diversos atores nem sempre estão concatenados.

Contudo, a participação democrática é a resultante do processo evolutivo das sociedades de massa. A exigência do reconhecimento do papel da população para a elaboração de políticas públicas já estava prevista no texto da Agenda 21 Global, elaborada na Conferência das Nações Unidas sobre Meio Ambiente e Desenvolvimento (CNUMAD), ocorrida na cidade do Rio de Janeiro em junho de 1992. Do texto se conclui que a Agenda viria a ser "[...] um instrumento de políticas públicas para o desenvolvimento sustentável, de construção e implementação coletiva - com participação de todos os segmentos da sociedade, compartilhando responsabilidades na consolidação dos planos de ação governamental" (MMA, 2004, p. 07).

E é justamente nas cidades, por certo por força da concentração demográfica, onde os conflitos são mais perceptíveis, próximos aos cidadãos. Deste modo, expandiu-se o acesso do cidadão na decisão da política urbana, na esfera local. Se antes os debates abordavam grandes temas surgidos no cenário internacional (uso de armas nucleares, epidemias, II Guerra Mundial, etc.), hoje as demandas locais ganham destaque na atenção dos sujeitos diretamente envolvidos, como pode ser observado em notícias que relatam os conflitos surgidos por problemas derivados da ocorrência de enchentes, da prestação deficitária de serviço de transporte público, da falta de creches, etc. (IASI, 2013, p. 43).

O presente artigo se ocupa em discutir os canais de participação do cidadão na construção da municipalidade, sua validade, sua legitimidade, e, na medida do possível, traçar perspectivas para o avanço no tema.

Para tanto, é proposto como objetivo geral estudar as perspectivas atuais para a participação democrática na política urbana brasileira construída com a Constituição de 1988. Os objetivos específicos são: estabelecer o que diz a Constituição sobre a participação democrática; 
conhecer o conteúdo jurídico-institucional da política urbana brasileira; e analisar os canais de participação democrática na política urbana brasileira.

O trabalho se justifica pela necessidade de estudar o fenômeno urbano brasileiro, o qual, comparado a outros países, é recente. E com tal conhecimento sugerir instrumentos com o intuito de minimizar os conflitos surgidos nas municipalidades, as quais, em menos de quarenta anos, receberam a maior parcela da população brasileira, migrante do meio rural.

\section{A EXIGÊNCIA DE PARTICIPAÇÃO POPULAR NA ELABORAÇÃO DE POLÍTICAS PÚBLICAS}

O artigo 25 do Pacto Internacional dos Direitos Civis e Políticos estabelece que todo cidadão terá o direito e a possibilidade de participar da condução dos assuntos públicos, diretamente ou por meio de representantes livremente escolhidos. O Comitê de Direitos Humanos das Nações Unidas, em seus Comentários Gerais n.25, afirmou que:

The conduct of public affairs... is a broad concept which relates to the exercise of political power, in particular the exercise of legislative, executive and administrative powers. It covers all aspects of public administration, and the formulation and implementation of policy at international, national, regional and local levels. ${ }^{3}$ NAÇÕES UNIDAS, 1996, par.5)

O modo como será feita essa alocação de poder estará estabelecido no texto da Constituição Federal e na legislação infraconstitucional. E continuam os Comentários Gerais:

Citizens may participate directly by taking part in popular assemblies which have the power to make decisions about local issues or about the affairs of a particular community and in bodies established to represent citizens in consultation with government. ${ }^{4}$ (NAÇÕES UNIDAS, 1996, par.6)

A comunidade internacional reconhece que o direito de participação envolve o direito de ser consultado na elaboração de leis e de políticas públicas e exige um verdadeiro compromisso de dialogar intensamente sobre a elaboração e desenvolvimento de políticas públicas.

\section{O conteúdo da participação democrática no texto constitucional}

\footnotetext{
${ }^{3} \mathrm{~A}$ condução dos assuntos públicos, é um conceito amplo que se relaciona com o exercício do poder político, em particular o exercício dos poderes legislativo, executivo e da administração. Ela cobre todos os aspectos da administração pública, e a formulação e a implementação de políticas nos níveis internacional, nacional, regional e local. (Tradução nossa).

4 Oscidadãospodemparticipardiretamentepelaparticipaçãoemassembléiaspopularesquetenham o poder de decisão sobre assuntos locais ou sobre assuntos de uma comunidade particular e em órgãos estabelecidos para representar os cidadãos diante do governo. (Tradução nossa).
} 
Participação pode ser entendida por diversas matizes, uma vez que se estende da participação em determinada agremiação esportiva até o processo eleitoral em todos os seus desdobramentos. Visando os objetivos deste estudo, a palavra participação está delimitada no processo onde o indivíduo, ou organizações legitimadas por determinados grupos, atuam dentro de um jogo de poder no cenário político vigente, dentro de uma ordem democrática que o recepciona.

A expressão "Participação Política" pode ser entendida como:

O termo participação, tomado em sentido estrito, poderia ser reservado, finalmente, para situações em que o indivíduo contribui direta ou indiretamente para uma decisão política. Esta contribuição, ao menos no que respeita à maior parte dos cidadãos, só poderá ser dada de forma direta em contextos políticos muito restritos; na maioria dos casos, a contribuição é indireta e se expressa na escolha do pessoal dirigente, isto é, do pessoal investido de poder por certo período de tempo para analisar alternativas e tomar decisões que vinculem toda a sociedade (BOBBIO, MATTEUCI, PASQUINO, 2010, p. 888).

A intervenção dos cidadãos no processo de tomada de decisões políticas normalmente se dá de modo indireto, ou seja, por meio de um representante legitimado para tal. Contudo, não estão excluídas ocasiões especiais onde a vontade do cidadão é explicitada de modo direto sem a intervenção de intermediários.

Em ambos os casos surge a necessidade do estabelecimento de regras que organizem o processo de tomada de decisões políticas. No contexto brasileiro as regras são primariamente determinadas pela Constituição Federal de 1988, que nasce após um período de aproximadamente vinte anos de ditadura militar, iniciado em 1964, e sob a presença de grandes manifestações para a retomada dos direitos civis e políticos, inclusive com a vigilância direta do cidadão na gestão do poder público.

Pereira (2010) lembra que a participação só é possível dentro de um regime democrático, onde a população é envolvida num ambiente onde a vida em sociedade é construída de modo coletivo, sendo o Estado apenas uma estrutura material para garantir o bem-estar desta população:

Entendemos que o papel do povo é, antes de tudo, garantir o relacionamento com o governo. Ou seja, é a participação popular nos movimentos políticos e sociais que propicia transformações efetivas de cidadania através de caminhos legítimos para garantir o cumprimento dos deveres e o exercício dos direitos consagrados pela Constituição (PEREIRA, 2010, p. 151). 
O texto constitucional vigente ficou conhecido como "Carta Cidadã" ${ }^{5}$ uma vez que, no plano formal, garantiu diversos direitos e canais de participação do cidadão brasileiro. Neste sentido, o parágrafo único, do Artigo 10 do texto constitucional é enfático ao expressar que um dos fundamentos do Estado Democrático de Direito instituído na República Federativa do Brasil, é reconhecer que "[...] todo o poder emana do povo, que o exerce por meio de representantes eleitos ou diretamente".

A atuação da população no processo de gestão do poder instituído é o elemento central da diferença existente entre o Estado de Direito e o Estado Democrático de Direito. No primeiro caso a atuação estatal se limita a atender o Direito instituído, preocupando-se em atender o princípio de legalidade. Já no segundo caso, adotado pelo Brasil, a relação entre a infraestrutura estatal com os respectivos detentores do poder político e a população governada carece de maior confiança e aceitação que são garantidas por eleições periódicas, para a validação dos mandatos, envolvendo a maior parte possível da população.

A parte final do parágrafo único, do referido Artigo 1ํㅡㄹ deixa expresso que em qualquer uma das hipóteses de exercício do poder cívico, o mesmo será dará "[...] nos termos desta Constituição", ou seja, necessariamente deverá obedecer ao texto constitucional. A ideia é reiterada - mas dessa vez voltada à Administração Pública - no artigo 37, caput, da Constituição, haja vista que todas as ações do poder público, inclusive agindo na consolidação da vontade política dos cidadãos, são legitimadas quando dentro dos limites impostos pela lei, e sua respectiva hierarquia ${ }^{6}$.

Apesar desta constatação, a letra fria da lei não é suficiente para alcançar o bem comum, obrigando o poder púbico a evoluir no sentido de se consolidar como Estado Democrático de Direito, onde a governabilidade é alcançada com uma relação de confiança envolvendo a coletividade, ao invés do uso deliberado da força:

Legalidade não significa a mesma coisa que legitimidade. A legalidade repousa na força e no poder. A legitimidade tem o seu fundamento no consenso e na aceitação das regras de conduta pelo povo. Em grau mais elevado, a legitimidade deve fundamentar-se ainda no sentimento da justiça,

\footnotetext{
${ }^{5}$ Caggiano (2002) reconhece que a Constituição de 1988 ampliou a participação política através da expansão da inserção de novos atores políticos, e a adoção de institutos destinados a interferir diretamente no pólo do poder, porém, complementa a autora: “[...] resta ainda prejudicada a figura do cidadão-eleitor, demandando-se, pois, ações precisas no sentido de assegurar ao cidadão brasileiro, na sua plenitude, a possibilidade de alcançar esse status" (CARTAGGIANO, 2002, p. 555).

${ }^{6}$ Neste sentido: "[...] todas as normas que integram a ordenação jurídica nacional só serão válidasse conformarem com as normas da Constituição Federal" (SILVA, 2016, p. 48).
} 
no ideário da justiça social e de bem-estar da comunidade (FERREIRA, 1989, p. 33).

Para que o poder público no Brasil seja legítimo, o mesmo deve contar com a participação dos cidadãos nos limites determinados pela Constituição Federal e demais leis infraconstitucionais. E a Constituição, já em seu artigo $1^{\circ}$., parágrafo $1^{\circ}$., estabelece que o povo exercerá o poder "[...] por meio de representantes eleitos". Daí que a vontade do cidadão se realiza de modo indireto por meio do voto. O texto constitucional adotou o conceito de sufrágio universal visando trazer para o processo eleitoral a maior gama possível de atores historicamente excluídos.

A primeira parte do Artigo 14 do texto constitucional é clara ao expressar que "[...] a soberania popular será exercida pelo sufrágio universal e pelo voto direto e secreto, com valor igual para todos". Comumente as palavras sufrágio e voto são empregados como sinônimas, mas José Afonso da Silva esclarece que o referido Artigo 14 exprime que sufrágio é identificado como sendo "universal", enquanto que o voto tem características específicas, tais como sendo direto, secreto, e com valor igual. Sendo assim, entende que tais elementos instrumentalizam a participação popular onde um se trata de um direito, o sufrágio, e o outro o exercício deste direito, o voto (SILVA, 2016, p. 350).

Deste modo, pode-se dizer que sufrágio "[...] é o poder que se reconhece a certo número de pessoas (o corpo de cidadãos) de participar direta ou indiretamente na soberania, isto é, na gerência da vida pública" (BONAVIDADES, 1994, p. 228).

O texto constitucional igualou homens e mulheres em direitos e obrigações, inclusive no tocante aos direitos políticos, e no parágrafo 1 ํㅡ, do Artigo 14, permitiu o voto de menores de 18 anos e dos analfabetos.

Apesar da Constituição de 1988 ter adotado o sufrágio como sendo o de modelo universal, seguindo uma tendência nas democracias ocidentais de massa consolidadas no Século XX, especialmente no pós-II Grande Guerra, Bonavides (1994) alerta para eventuais restrições, tais como: nacionalidade, idade, capacidade física ou mental, indignidade, serviço militar, e alistamento.

O atual sistema brasileiro permitiu uma expansão no número de eleitores, pois no passado político do País os homens de baixa renda, mulheres, e analfabetos eram excluídos do processo eleitoral. Caggiano (2002) lembra que a tradição política brasileira no período de transição entre monarquia e república não tinha seu foco na participação da massa de cidadãos presentes naquele período, ao contrário, as câmaras e assembleias eram frequentadas pelos chamados "homens bons" e os "homens novos", sendo que os primeiros eram caracterizados pelos nobres e seus 
descendentes, senhores de engenho, alta burocracia civil e militar (e seus descendentes); já os segundos eram compostos da burguesia recém-enriquecida pelo comercio urbano. $\mathrm{O}$ advento da República não garantiu de imediato o reconhecimento do voto feminino, mesmo sendo uma bandeira dos republicanos civis.

A República brasileira nasce de um processo onde "[...] a colaboração do elemento civil foi quase nula" (FAORO, 2012, p. 607-608), prevalecendo os interesses corporativos dos militares que foram obrigados, no período seguinte, a usar deliberadamente a força. O apoio dos intelectuais civis não foi suficiente para influenciar significativamente no ambiente político, pois, segundo Faoro (2012), os militares estavam mais organizados que os partidos republicanos dispersos. Como resultado, eclodiram diversos focos de conflitos surgidos no território nacional, e "pacificados" pelo uso extremo da violência do governo militar sediado na cidade do Rio de Janeiro. Sem contestação do poder instituído, diversos privilégios, tradições, e costumes existentes no período monárquico permaneceram intocáveis, em especial em favor das oligarquias próximas ao poder.

Enquanto a elite burocrática cuidou dos próprios interesses, a grande massa da população, formada por pequenos comerciantes, escravos libertos, e imigrantes europeus recém-chegados, mas na sua maioria analfabeta e desprovida de riquezas, permaneceram incapacitados de influenciar o cenário político.

A democracia implantada junto com a república foi importada por uma aristocracia rural e semifeudal que garantiu, por meio de uma "decoração externa", seus direitos e privilégios, enquanto que a massa popular quase sempre era pega de surpresa pelas "reformas" impostas de cima para baixo. Neste período da Velha República fica evidente que "[...] a democracia no Brasil foi sempre um lamentável mal-entendido" (HOLANDA, 1995, p. 160).

Trata-se de um processo histórico conflituoso desenrolado ao longo do Século XX, atingindo o seu clímax num texto constitucional que ampliou as possibilidades de um cidadão comum intervir no cenário político. Restam, certamente, cicatrizes na alma da sociedade brasileira as quais interferem na consolidação de uma maior consciência e participação cívica.

Os instrumentos de participação no cenário político estão disponíveis em favor do cidadão na legislação, ampliados para além do simples voto em período de eleições ainda que nem sempre o cidadão esteja devidamente engajado para o seu uso.

O Artigo 14 da Constituição de 1988 amplia tais instrumentos quando prevê a participação direta por meio do plebiscito, referendo e da iniciativa popular. Além destes institutos de intervenção direta da população na vida política do País, Silva (2016) ainda arrola a Ação Popular, a 
qual "[...] consiste na possibilidade de qualquer membro da coletividade, com maior ou menor amplitude, invocar a tutela jurisdicional a interesses coletivos" (SILVA, 2016, p. 462).

Bonavides (1994, p. 274), ao tratar dos writs do referido Artigo 14 da Constituição de 1988, entende que estes instrumentalizam a "democracia semidireta", uma vez que a democracia direta é aquela exercida pelo antigo cidadão ateniense na Ágora, quando decidiam os rumos da CidadeEstado, modelo, aliás, impossível de ser retomado pelos grandes estados nacionais da atualidade.

A fim de caracterizar tais institutos, entende-se que:

[...] o constitucionalismo democrático da idade contemporânea, mais intimamente ligado às aspirações da doutrina da soberania popular, elegeu alguns instrumentos de participação, que dão ao povo, conservadas embora em partes as formas representativas, a palavra final relativa a todo o ato governativo (BONAVIDES, 1994, p. 281).

A Constituição Brasileira de 1998 seguiu uma tendência surgida notadamente nos países europeus. Se na primeira metade do Século XX o referendo foi utilizado para os mais diversos temas, dos mais complexos aos mais banais, como, por exemplo, a mudança de lado da rua para o trânsito de veículos, a partir da década de 1970 o instituto foi utilizado para questões com repercussão macro política, tais como consultas destinadas a decidir sobre o ingresso, ou não, na Comunidade Europeia ${ }^{7}$; países com crises separatistas; eventuais mudanças nas formas de regime político ou de governo; casos onde se acelerou, ou bloqueou, a transição entre regimes autoritários para democráticos (MOISÉS, 2002, p. 65-66).

Moisés (2002), em quadro comparativo, demonstra que de 1900 a 1980 a Suíça, comparada com quinze países, dentre eles França, Itália, Alemanha e Reino Unido, valeu-se do referendo em 252 ocasiões, bem à frente da Austrália, o segundo colocado, com 18 referendos. Entende o autor que há uma longa tradição suíça referente ao instituto, que assume características mandatórias, ou seja, uma vez se obtendo a maioria exigida no processo de referendo é possível, por exemplo, fazer cessar os efeitos de uma lei nacional, mesmo que regularmente aprovada no parlamento, ou, ainda, é possível requerer a revisão completa do texto constitucional daquele País.

No Brasil o uso destes institutos de consulta direta ainda é tímido. São instrumentos que poderiam auxiliar na legitimação política de iniciativas na esfera federal, estadual e municipal, notadamente sobre temas polêmicos e de grande clamor e interesse popular.

Para atender ao tema aqui proposto, os instrumentos de intervenção direta da população poderiam ser utilizados sistematicamente nas diversas municipalidades brasileiras, adequando a atividade dos poderes executivo e legislativo às necessidades locais. Essa possibilidade é percebida

${ }^{7}$ Inglaterra em 1975, e Noruega em 1972. 
principalmente após o advento da nova organização federativa onde município ganhou considerável destaque. De fato, o artigo 18 da Constituição Federal garantiu maior autonomia política uma vez que, no texto constitucional, as municipalidades deixaram de ser "[...] circunscrições territoriais meramente administrativas" (MEIRELLES, 2016, p. 672), para assumir o papel de importante peça do regime federativo, constituindo-se numa "[...] entidade estatal de terceiro grau" (SILVA, 2016, p. 620), inclusive podendo elaborar o próprio Plano Diretor.

Visando o desenvolvimento nacional, a Constituição, em seu artigo 174, parágrafo 1으, prevê a adoção sistemática do planejamento nas diversas esferas de poder, buscando a integração dos planos de gestão, inclusive no âmbito regional. E é aqui que se inserem os planos diretores municipais os quais, por força do Estatuto da Cidade, são formulados com a ampla participação da sociedade organizada em conferências, conselhos, e demais consultas públicas.

Como destaca Pereira (2010), no atual cenário jurídico-institucional brasileiro há a permissão legal para o acesso do cidadão na vida política do País, por meio de plebiscito, referendo, iniciativa popular de projeto de lei, e, acresce Silva (2016), a possibilidade de ajuizar ação popular. A Constituição Federal de 1988 ainda permitiu à legislação infraconstitucional a criação de canais de participação direta, como no caso da política urbana brasileira. O Brasil está vivendo um momento histórico onde o cidadão é chamado a participar efetivamente na construção da realidade do seu País, e, conforme o aqui estudado, também do município onde vive.

\section{O conteúdo da legislação infraconstitucional sobre políticas urbanas.}

Apesar da crítica de Bonavides (1994) sobre a impossibilidade da democracia direta em escala nacional, o legislador pátrio ampliou esta modalidade de participação em especial no nível local, ou seja, com normas infraconstitucionais o cidadão está autorizado a intervir diretamente na formulação da agenda política das cidades.

Trata-se da regulamentação dos artigos 182 e 183 da Constituição Federal de 1988 pela Lei n. 10.257/01, que consolidou o Estatuto da Cidade, onde está determinado um novo modelo de gestão compartilhada (VILLAÇA, 2005).

É uma legislação que impõe aos municípios a adoção do Plano Diretor como instrumento de gestão. Este instrumento surgiu na década de 1970como resposta à institucionalização do planejamento, numa época onde os Estados podiam elaborar as Leis Orgânicas Municipais, como foi o caso de municípios do Estado de São Paulo, Santa Catarina, Rio Grande do Norte, Pará, Mato 
Grosso, Alagoas e Ceará, que adotaram o plano diretor de desenvolvimento integrado. Nos demais Estados havia, nos seus respectivos municípios, meros planos de desenvolvimento.

No dizer de Saule Júnior (1997), a adoção de um plano diretor de desenvolvimento integrado era uma exigência dos Estados para o auxílio financeiro e transferência de recursos aos municípios e de tal mecanismo se valeu a União através do Serviço Federal de Habitação e Urbanismo (SERFHAU), o qual dispunha de um sistema de financiamento às prefeituras interessadas em aderir a um plano integrado de desenvolvimento.

Esta fase inicial de planejamento urbano extensivo não vislumbrava a participação popular na elaboração dos instrumentos de gestão, ao contrário, eram valorizadas as influências técnicas, políticas e econômicas. Tal contexto privilegiou as elites urbanas em detrimento das populações que estavam migrando, principalmente nas décadas de 1970 e 1980, do campo para a cidade.

A título de exemplo, George Martine ilustra o cenário daquele período:

Apesar da multiplicação do número de cidades, o padrão predominante de redistribuição populacional foi constituído, pelo menos até 1980, pela concentração crescente da população total em grandes megalópoles; na década de 70, por exemplo, as dez maiores cidades tiveram um crescimento total equivalente a $42 \%$ do aumento populacional do país. O município de São Paulo, sozinho, teve, durante a década de 70, um crescimento comparável ao da região Norte como um todo (MARTINE, 1996, p. 32).

Sobre este processo de urbanização, Melo (2010) esclarece que o acesso à terra urbana formal é repleto de obstáculos, os quais lançam boa parte da população a viverem em condições indignas e de insegurança. Entende a autora que o cenário é agravado pela especulação imobiliária, localização física de infraestrutura, centralização de serviços básicos, ausência de políticas habitacionais, dificuldade de acesso aos postos de trabalho, etc.

Como resposta ao encarecimento dos lotes urbanos, surge a "cidade ilegal" constituída pela ocupação de terrenos públicos e privados de modo precário.

Visando diminuir o distanciamento de uma considerável parte da população urbana no processo de desenvolvimento da cidade, surge um movimento destinado a clamar por mais espaço nas arenas de decisão, influenciando as agendas políticas. Um exemplo deste poder de influência foi observado na Assembleia Nacional Constituinte com a apresentação da Emenda Popular de Reforma Urbana, subscrita por movimentos sociais, tais como: a Articulação Nacional do Solo Urbano (ANSUR), Movimento de Defesa do Favelado (MDF), Federação Nacional dos Arquitetos (FNA), Federação Nacional dos Engenheiros (FNE), Coordenação Nacional dos Mutuários e Instituto dos Arquitetos do Brasil (IAB).Esta emenda influenciou significativamente o texto final dos artigos 
182 e 183 da Constituição Federal de 1988, garantindo a gestão democrática e o direito à cidade (SAULE JUNIOR, 1997).

Trazer novos atores à arena de decisão foi uma saída estratégica destinada a conter a insatisfação da população nos centros urbanos em expansão. A lei do Estatuto das Cidades surge após um período de agitação política que se iniciou com as propostas de Reforma de Base do Presidente João Goulart, onde já se abordava a democratização da terra urbana, passando pelo viés tecnicista dos governos militares do pós-1964, atingindo o seu ápice com a redemocratização trazida pela Constituição de 1988(SAULE JUNIOR, 1997).

A opção por um instrumento de gestão com caráter mais democrático foi uma resposta aos movimentos sociais e econômicos surgidos, inclusive, em escala global. Neste sentido, EspingAndersen (1995) trata que durante o século XX surgem as planificações estatais destinadas a tecer as metas e determinar os meios capazes de implementar as políticas sociais. O planejamento alcançou grande importância nos governos do Pós II Guerra ao longo do chamado "Anos Dourados", servindo na consolidação do Estado de Bem-Estar Social (WelfareState) na vigência do plano Marshall, que se encarregou de reconstruir os países devastados pela guerra (SANTOS, 2001).

Contudo, este modelo de desenvolvimento se revelou insustentável e foi adaptado no sentido de fortalecer as instituições coletivas capazes de negociar os interesses da população, empresários e Estado: como foi observado na Austrália que apesar de minimizar o protecionismo do trabalhador conseguiu manter a oferta de emprego; ou como nos EUA e Reino Unido onde a política de liberalização deu-se sem o envolvimento de sindicatos, permitindo maior flexibilidade do mercado de trabalho e salários(ESPING-ANDERSEN, 1995).

Como resposta ao atual capitalismo competitivo e com o intuito de atrair investidores estrangeiros, adotou-se no Brasil o modelo da administração pública gerencial que está fundamentada na redução dos custos operacionais e focada nos resultados em prol do cidadão. A reforma administrativa brasileira atendeu ao déficit no equilíbrio fiscal e às crises na estrutura político-administrativa do Estado, que, no modelo burocrático, não conseguiu atender às demandas da sociedade civil, por tratar-se de uma estrutura lenta, cara e ineficiente (PEREIRA, 1998).

O modelo gerencial nasceu inspirado na iniciativa privada, e foi adaptado ao setor público desdobrando-se até no âmbito municipal, onde foi criado, nos Estados Unidos, o chamado 
Planejamento Estratégico Municipal (PEM) ${ }^{8}$, o qual auxilia os gestores públicos, através da devida análise de dados coletados, a encaminharem suas decisões na formulação de ações em determinada localidade (REZENDE E CASTOR, 2005).A motivação à adoção dos instrumentos de gestão do novo gerencialismo público, de onde se destaca o planejamento estratégico municipal (FREY, 2004), foi desenvolvida na medida em que os governos municipais de orientação mais inovadora se comprometeram com o discurso democrático-participativo, enquanto que os grupos políticos mais conservadores e de linha neoliberal foram pressionados pelas crescentes demandas sociais.

O planejamento da ação pública refletiu, inclusive, no conteúdo da legislação, como pode ser observado no Artigo 40, caput, da Lei n.10.257/01, o qual expressa que "[...] o plano diretor, aprovado por lei municipal, é o instrumento básico da política de desenvolvimento e expansão urbana", e, para atingir seus objetivos, são vinculados às suas diretrizes o plano plurianual, as diretrizes orçamentárias e o orçamento anual (Artigo 40, § 1ํㅡ, Lei n.10.257/01).

Deste modo, é compreensível que as mudanças da economia internacional, assim como os debates surgidos nos movimentos sociais também em escala global, impactaram no texto da Constituição Federal de 1988, e, como resposta, foram ampliados os canais de envolvimento da população interessada.

O Estatuto da Cidade seguiu no sentido da participação popular, pois, visando a efetivação das arenas participativas, legitima os canais participativos no seu Artigo 43, incisos I a IV ${ }^{9}$, uma vez que determina o uso de instrumentos de "gestão democrática da cidade", tais como: os órgãos colegiados de política urbana (inciso 1);debates, audiências e consultas públicas (inciso II); conferências sobre assuntos de interesse urbano (inciso III); e iniciativa popular de projeto de lei e de planos, programas e projetos de desenvolvimento urbano (inciso IV).

O Estatuto da Cidade inovou o plano diretor ao estabelecer canais democráticos, reflexo do atual contexto jurídico-político. Nas fases de obtenção de informações, da elaboração, e da implementação do respectivo Plano Diretor há a necessidade da condução do processo pelo poder Executivo local, "[...] articulado com os representantes do poder Legislativo e com a sociedade civil" (CIDADES, 2005, p. 17).

Para o arquiteto e urbanista Marcelo Minghelli a cidadania está intimamente relacionada ao espaço público, que é "[...] o resultado da construção dos sujeitos sociais que nele interagem"

\footnotetext{
8 Internacionalmente conhecido como "City wide Strategic Planning".

${ }^{9}$ Lei Federal n. 10.257, de 10 de julho de 2001.
} 
(1995, p. 13). A solução dos problemas desenvolvidos, inclusive ambientais, no interior das urbanidades está no planejamento que "[...] pode ser transformado em instrumento de democratização no processo de expansão e administração das cidades, ao invés de um processo tecnocrático e autoritário" (RATTNER, 2005).

Há uma tendência em ascensão na doutrina e atividade especializada em conciliar os saberes percebidos nas populações locais, conjugados com o conhecimento técnico dos profissionais especializados, visando a melhoria na qualidade de vida das pessoas envolvidas.

\section{OS CANAIS DE PARTICIPAÇÃO DEMOCRÁTICA NA POLÍTICA URBANA BRASILEIRA}

A novidade histórica no caso brasileiro é a cidade democratizada, pois o processo de consolidação do território nacional, por longo período, visou a eficiência de um empreendimento colonial de extração dos recursos naturais. Neste sentido, o médico Luís Pereira Barreto, republicano e positivista ${ }^{10}$, em 1880 escreveu no periódico "A Província de São Paulo" uma crítica à monarquia portuguesa a qual não foi capaz de criar uma nação no vasto território sob o seu jugo, ao contrário, preponderou, mesmo após a independência, os interesses de uma família, a imperial, seguida em segundo lugar pelos interesses "de uma pequena raça" de afortunados próximos ao poder, ambas sustentadas sobre o trabalho exaustivo de uma massa de indivíduos escravizados. 0 autor ainda esclarece que o interesse da elite naquele momento com a vinda das grandes levas de imigrantes europeus, no final do Século XIX, não era garantir a cidadania destes, mas mantê-los em total dependência dos detentores do poder, ou seja, "[...] desistimos do escravo negro, mas queremos o escravo branco sob o nome mais eufônico de colono" (BARRETO, 2007, p. 43).

No dizer de Holanda (1995, p. 176) na consolidação da República não houve a formação de um patriciado capaz de influenciar as principais instituições no sentido de fortalecer a unidade nacional. Ao contrário, como salienta o autor, o poder restou nas mãos de uma plutocracia apática incapaz de deixar um legado de virtudes no ambiente público. O resultado é um País sem tradição de cidadania, gerido conforme os interesses da sua elite nacional e, nas últimas décadas, pressionado pela força do mercado globalizado.

Com a recente retomada da democracia muitas ações surgidas no meio popular direcionaram suas forças na direção de reconhecer a atuação da sociedade civil organizada. $O$

${ }^{10}$ Conforme Holanda (1995, p.159) no período de transição entre o Império e a República surgiu muitos intelectuais identificados com o positivismo de Augusto Comte. Estes vislumbravam uma nova ordem política baseada no racionalismo no trato da coisa pública. Contudo, esclarece o autor, não foram além da retórica, zelando, entretanto, dos próprios interesses. 
texto constitucional disponibilizou ao cidadão comum instrumentos os quais permitem a influência direta na vida política do País, seja na esfera nacional, regional ou local. Vários são os instrumentos os quais colocam o cidadão como ator ativo na gestão de diversas políticas públicas ${ }^{11}$.

A participação não prescinde da atuação do Estado, a sociedade participa: "[...] na esfera pública - via conselhos e outras formas institucionalizadas - não é para substituir o Estado, mas para lutar para que este cumpra seu dever: propiciar educação, saúde e demais serviços sociais com QUALIDADE, e para todos" (GOHN, 2004, p.24).

A interferência popular nos assuntos públicos subsiste mesmo que em paralelo aos espaços institucionalizados, mas com o novo cenário político brasileiro os anseios populares estão sendo, na medida do possível, convertidos em políticas públicas, como é o caso da Lei Federal n.10.257/01, em especial nos Artigos 43, 44 e 45, a qual reconhece a atuação da comunidade e das organizações que nela agem. Contudo, a lei é ampla ao descrever os canais participativos e os meios de influenciar no texto final da lei do plano diretor, deixando lacunas a serem preenchidas.

O presente estudo determina o seu escopo ao estudar a intervenção popular na gestão da cidade, notadamente no processo de composição do órgão de representação coletiva, que intervém na elaboração do respectivo Plano Diretor. Como foi aqui demonstrado, o cenário político brasileiro nas últimas décadas tendeu da centralização do poder à abertura democrática, tendo em paralelo um processo de adensamento das cidades com a migração do meio rural:

A cidadania nos anos 1990 foi incorporada nos discursos oficiais e ressignificada na direção próxima à ideia de participação civil, de exercício da civilidade, de responsabilidade social dos cidadãos como um todo, porque ela trata não apenas dos direitos, mas também de deveres, ela homogeneíza os atores (GOHN, 2004, p.23).

A Lei Federal n.10.257/01, conhecida como Estatuto da Cidade, apresentou canais de participação direta, contudo, há muito por se fazer haja vista os interesses arraigados nos municípios dos grupos econômicos historicamente próximos ao poder. Um grande entrave à democratização do espaço urbano reside justamente na atividade dos grupos que lucram com a especulação imobiliária, lançando boa parte da população urbana na degradação social e distante na formulação da agenda de políticas públicas (MARICATO, 2013).

A precariedade dos laços sociais também está refletida na organização institucional do poder público, o qual historicamente serviu aos interesses de uma determinada elite próxima ao poder político e econômico:

\footnotetext{
${ }^{11}$ Neste sentido, ver os Artigos 187, caput; 194, VII; 198, III; e 204, II, todos da Constituição Federal de 1988.
} 
[...] frequentemente, o baixo nível de institucionalização esteve vinculado às resistências corporativas à implementação de práticas participativas, sempre que vinham à tona questões como controle, fiscalização e deliberação por parte da comunidade (JACOBI, 2002, p. 449).

E foi dentro deste contexto que nasceu o Estatuto da Cidade, onde estão previstos diferentes canais para que se concretize a gestão democrática da cidade. Um deles é a possibilidade de participação em órgãos colegiados de política urbana, sendo que o principal identificado no nível local é o conselho da cidade que congrega membros oriundos do poder público, da sociedade civil organizada, dos empresários, dos prestadores de serviços, e da academia $^{12}$.

A diversidade de atores atuantes no interior dos conselhos faz destes órgãos plurais e híbridos. Sua natureza consultiva e, ou, deliberativa é legitimada pela Constituição Federal de 1988, a qual determinou que as diversas políticas públicas sejam formuladas em conjunto com as deliberações dos respectivos conselhos gestores (AVRITZER; PEREIRA, 2005).As dificuldades fazem com que a participação popular no plano diretor seja encarada como uma grande ilusão, uma vez que a população comparece nas audiências públicas em número inexpressivo, e quando o faz assume uma postura passiva diante das exaustivas exposições dos técnicos urbanos nas solenidades oficiais (VILLAÇA, 2005).

De acordo com este autor, a desigualdade social existente no País é a responsável pela dificuldade em mobilizar a população a participar de um ambiente de consolidação de uma política pública participativa. Ademais, quando a população é chamada a participar a agenda já está preestabelecida e, na maioria dos casos (VILLAÇA, 2005), os temas não estão em sintonia com a realidade dos convidados, ensejando o desinteresse no tema. Nesse sentido:

[...] a maior parte dos estudos indica que os conselhos possuem uma baixa capacidade de inovação das políticas públicas a partir da participação da sociedade civil nos conselhos, sugerindo que essa participação assume contornos mais reativos que propositivos (TATAGIBA, 2002, p. 92).

Resta a impressão que as solenidades públicas destinadas à elaboração, ou revisão, dos planos diretores municipais estão mais para receber o endosso da população que promover o efetivo debate em torno dos problemas das cidades. E mesmo que a comunidade tenha voz ativa nos eventos de debate, é bem provável uma inépcia generalizada em relação aos assuntos ligados à cidade. A existência dos conselhos permite ao poder público dar transparência dos seus atos e, ainda, capacitar o cidadão comum nos assuntos de interesse público, permitindo, assim, maior efetividade da participação comunitária (KLEBA, COMERLATTO, FROZZA, 2015).

\footnotetext{
${ }^{12}$ Conforme o Artigo 43, I, do Estatuto da Cidade.
} 
Apesar das dificuldades, inclusive com a cultura e costumes vigentes da sociedade brasileira, ainda há um grande espaço para aprimoramentos, principalmente no sentido de melhorar a participação em conselhos visando que tal influência da população possa ser deliberativa, sem, no entanto, sofrer entraves impostos por aqueles que historicamente tomaram as decisões.

Conforme o tempo vai se distanciando da data de promulgação da Constituição Federal de 1988, é natural que haja um número cada vez maior de conselhos atuantes. Mas se em um primeiro momento o desafio era sua instalação e estabelecimento de regras para seu funcionamento, os desafios atuais são de outra ordem:

Precisamos de mudanças na prática cotidiana dos conselhos que confiram maior centralidade ao exercício da política, em lugar da rotina burocrática da gestão. Estamos entendendo política como a ação que traz para a arena pública demandas por justiça que interpelam consensos e regras instituídas. Uma ação, portanto, que legitima e arma conflitos na sociedade visando, mediante negociações públicas, a redefinição dos termos sobre os quais se organizam o Estado e a sociedade. É preciso restituir o lugar desse tipo de ação na agenda dos conselhos para que eles possam funcionar como instâncias de democratização da gestão pública, e não restritamente como espaço de disputa entre interesses corporativos das comunidades de política, o que hoje parece ser a regra. (ALMEIDA; TATAGIBA, 2012, pp.7172)

A fim de minimizar a "ilusão" de uma possível participação popular, a qual ainda é mais opinativa que deliberativa, é fundamental recorrer ao conceito de cidadania na legislação brasileira. A participação só é possível quando vigente um regime que atenda ao princípio democrático, como foi adotado no Brasil desde 1988. Neste ambiente institucionalizado "[...] o exercício do poder que emana do povo é uma responsabilidade que deve ser cumprida cotidianamente através da participação popular" (PEREIRA, 2010, p. 151).

A palavra participação, dentro de um regime democrático, está diretamente ligada ao conceito de cidadania, pois nem todos os indivíduos presentes em dada organização política estão autorizados a legitimar um processo, opinar, ou influenciar determinada situação. Deste modo, conclui-se que há uma "medida" para a cidadania.

Em relação à realidade do contexto brasileiro, o cidadão carece de identificação para expressar sua vontade no cenário político:

Os direitos de cidadania adquirem-se mediante alistamento eleitoral na forma da lei. O alistamento se faz mediante a qualificação e inscrição da pessoa como eleitor perante a Justiça Eleitoral [...]. Pode-se dizer, então, que a cidadania se adquire com a obtenção da qualidade de eleitor, que 
documentalmente se manifesta na posse do título de eleitor válido (SILVA, 2016, p.347-348).

O autor se refere à qualificação dos participantes da vida do Estado, direito este consagrado no Parágrafo 1ำ, do Artigo 14 da Constituição Federal de 1988. No tocante ao estudo aqui desenvolvido, é relevante identificar o indivíduo que pretende interferir numa determinada municipalidade a fim de identificar se o mesmo tem alguma relação com a realidade onde pretende interferir. Há a necessidade real de desenvolver ritos próprios para os processos participativos identificados na política de desenvolvimento urbano a fim de se evitar possíveis fraudes. Neste sentido:

Os procedimentos exigidos [no processo eleitoral tradicional] são necessários porque se configuram como imperativos de segurança para que a soberania popular não venha a ser maculada por fraudes eleitorais. A finalidade da existência de ritos complexos se configura como procedimental, no intento de assegurar a transparência do alistamento, o que garante o devido processo legal, o contraditório e a ampla defesa (VELLOSO; AGRA, 2010, p. 144).

A justiça eleitoral existe para garantir a verdade formal identificada no processo de escolha dos representantes dos cidadãos, legitimando, assim, atores para interferir na gestão da macroestrutura publica, nas três esferas de poder: nacional, regional e local.

Com as mudanças implantadas desde 1988, onde o cidadão comum dispõe de novos espaços de intervenção na agenda política, é também possível que haja evoluções no sentido de envolver a justiça eleitoral na política pública de desenvolvimento urbano, no tocante ao processo de escolhas de representantes dos respectivos conselhos de cidades, haja vista a necessidade de legitimidade destes ao falarem em nome de uma comunidade.

A questão crucial do processo eleitoral é saber se um indivíduo tem condições de votar e de ser votado. Daí a necessidade de identificar o domicilio eleitoral do sujeito, pois é possível que o mesmo manifeste a sua vontade em regiões diversas, sem, no entanto, dispor de qualquer relação com a mesma, apenas atendendo a interesses escusos. A vinculação geográfica do eleitor é feita, por exemplo, nos sistemas que comportam o voto é distrital, onde são identificados como eleitores os indivíduos que têm laços com a região geograficamente delimitada, no caso, o distrito eleitoral (CERQUEIRA; CERQUEIRA, 2011, p. 125).

O sistema brasileiro reconhece que o domicílio eleitoral é determinado pelo local onde o eleitor apresente "vínculo material ou afetivo", não sendo necessário que se trate do local da sua residência, como é determinado pela lei civil, basta a comprovação de laços de conteúdo político, 
comercial, comunitário, familiares, etc. (VELLOSO, AGRA, 2010, p. 150; CERQUEIRA, CERQUEIRA, 2011, p. 371).

Tal identificação, além de evitar que um mesmo indivíduo vote diversas vezes em locais diferentes, comprometendo, assim, a confiança em todo o processo de escolha de representantes, estimula o vínculo deste com a comunidade onde está inserido fortalecendo o seu ânimo para participar da vida pública que diretamente Ihe afeta. É uma questão de trazer legitimidade ao processo político, mesmo que este seja nas novas arenas de participação, menos formais e mais próximas das comunidades. Contudo, é necessário o mínimo de institucionalização para a participação mesmo diante de grandes desafios, eis que:

[é] permeada de dificuldades decorrentes da heterogeneidade dos grupos comunitários e associativos, o que torna complexos os problemas de representação, criando tensões quanto aos critérios de escolha, acirrando a concorrência e trazendo à tona a pressão dos grupos organizados no sentido de reforço das práticas neocorporativas. Isso provoca, frequentemente, um esvaziamento destes mecanismos de decisão coletiva. (JACOBI, 2002, p. 450).

As limitações e os conflitos identificados no quotidiano das comunidades brasileiras ainda pressionam no sentido da busca de soluções e evolução dos instrumentos jurídicos vigentes, pois o próprio Estatuto da Cidade deixa transparece uma lacuna referente a participação direta da população, uma vez que, em regra geral, a intervenção no poder por meio democrático se faz pela qualificação do cidadão. Tal lacuna se refere ao processo de criação de uma lei municipal, o plano diretor, onde há a interferência, inclusive, de pessoas jurídicas agindo em nome da comunidade, no caso, no interior do respectivo conselho da cidade. Não estão explícitos no texto do Estatuto da Cidade os meios que garantem a legitimidade da sociedade civil organizada quando interferem na elaboração e revisão do plano diretor municipal, cabendo, assim, inovações no sentido de preencher a lacuna aqui identificada, referente a legitimidade dos atores envolvidos no processo.

A população intervindo diretamente na política urbana se assemelha à democracia ateniense, onde, conforme apenas os cidadãos de famílias tradicionais na Cidade-Estado estavam autorizados a intervir na vida pública, excluindo os escravos e os estrangeiros (BONAVIDES, 1994, p. 269). Neste sistema os cidadãos eram identificados e qualificados, visando o bem coletivo da cidade-estado ateniense. Uma das limitações ao sufrágio, ou direito de intervenção na vida pública, é o alistamento eleitoral (BONAVIDES, 1994, p. 237). Para que tal prerrogativa, inerente à cidadania, realize-se é necessário criar instituições capazes de identificar o cidadão, captar sua vontade política de modo livre e objetivo, processar tal vontade, e converter na escolha de indivíduos os quais irão exercer a função pública. 
No sistema político vigente no Brasil apenas as pessoas com título de eleitor estão autorizadas a legitimar seus representantes no poder político, logo, é necessário que cidadãos devidamente identificados e qualificados pela justiça eleitoral possam intervir na elaboração do plano diretor das cidades onde habitam, pois no modelo atual grupos estão agindo sem qualquer comprovação da sua relação com a comunidade onde pretendem intervir com suas respectivas deliberações.

Um exemplo deste fenômeno foi observado no processo de revisão do Plano Diretor da Cidade de Curitiba/PR, ocorrido no biênio 2014-2015. A escolha dos representes que compuseram o Conselho da Cidade de Curitiba (CONCITIBA) ocorreu na 5a Conferência Municipal da Cidade de Curitiba (COMCURITIBA), realizada nos dias 10 e 11 de maio de 2013. A Resolução n. 25, de 1o de abril de 2013, do CONCITIBA, que trata do regimento interno da 5a COMCURITIBA, deixa evidente que o evento teve como objetivo, inclusive, estimular a ampla participação dos diversos segmentos da sociedade.

No processo de escolha dos membros que viriam a compor o CONCITIBA, as regras da referida Resolução n. 25 limitaram o acesso da diversidade de atores existentes na cidade, uma vez que a regra impôs o acesso ao voto dos delegados desde que os mesmos estivessem devidamente inscritos previamente na 5a COMCURITIBA, e para tal tiveram que comprovar a presença das organizações, nas quais atuavam, na discussão do desenvolvimento urbano em outras ocasiões. Neste sistema, por exemplo, uma Associação de Pais e Mestres de um bairro da periferia da cidade, ou um simples morador, não poderiam expressar sua vontade na escolha dos conselheiros pela falta de algum documento que comprovasse a participação em outros eventos destinados a debater os temas específicos do desenvolvimento urbano, tais como: Habitação, saneamento, transporte público, etc.

Uma solução para inovar este modelo é exigir que os candidatos ao conselho sejam atuantes em organizações vinculadas aos temas de desenvolvimento urbano, como está sendo feito, mas que a escolha dos mesmos seja por votação dos cidadãos presentes na respectiva conferência, os quais comprovassem a sua relação com o município através do título de eleitor, como é exigido na escolha dos vereadores e do prefeito.

Daí a necessidade de envolvimento da Justiça Eleitoral por ocasião da elaboração ou revisão do plano diretor, uma vez que "[...] a Justiça Eleitoral tem como escopo realizar a "verdade eleitoral" como forma de efetivar a democracia" (VELLOSO; AGRA, 2010, p. 30). O envolvimento do poder judiciário nos processos de democracia direta, como no caso da escolha dos conselheiros, 
trará maior legitimidade jurídica quando identificados os legítimos cidadãos autorizados a atuar em nome da coletividade.

A lei eleitoral visa qualificar o cidadão inclusive vinculando-o a uma base geográfica determinada, Como se observa no Artigo 42, parágrafo único, do Código Eleitoral, auxiliando, assim, na identificação dos indivíduos capazes de traçar diagnósticos reais da municipalidade, e informar os anseios das suas comunidades, haja vista a identificação formal da sua condição de morador da localidade a qual traz maior legitimidade ao processo.

No modelo atual não há garantias sobre o perfil das pessoas que estão intervindo no processo, não está claro se estas têm algum vínculo com a realidade local, e, ainda, fica a dúvida se estas agem por interesses coletivos ou individuais.

Os desafios para que a participação seja efetiva são muitos, e:

[...] estão intrinsecamente vinculados à predisposição dos governos locais de criar espaços públicos e plurais de articulação e participação, nos quais os conflitos se tornam visíveis e as diferenças se confrontam, como base constitutiva da legitimidade dos diversos interesses em jogo. (JACOBI, 2002, p.452)

A participação nas políticas pública é uma novidade que ainda não foi absorvida pelo próprio poder público, cabendo inovações e ajustes constantes até atingir um grau aceitável de excelência. É razoável admitir que há evoluções neste tema, principalmente depois da criação do Estatuto da Cidade:

O que se constata a partir dos vários estudos é o fato de que tem sido muito difícil reverter, na dinâmica concreta de funcionamento dos Conselhos, a centralidade e o protagonismo do Estado na definição das políticas e das prioridades sociais, apesar de a própria existência dos Conselhos já indicar uma importante vitória na luta pela democratização dos processos de decisão (TATAGIBA, 2002, p. 55).

A questão é ampliar o acesso do cidadão comum para que o mesmo não seja cooptado por grupos acostumados à proximidade com o poder. O aprofundamento das pesquisas sobre o tema vai, aos poucos, identificando o que ainda pode ser feito para melhorar a participação popular na elaboração de políticas públicas em geral, e nas que versam sobre o tema urbano, em particular. 0 equívoco é aceitar sistemas engessados incapazes de admitir inovações que tragam benefícios à coletividade, como a aqui proposta.

\section{CONCLUSÃO}

A população brasileira ainda não está motivada e consciente da importância da participação nas audiências, e demais canais, que conferem legitimidade ao plano diretor local, 
mas a discussão de melhorias nos instrumentos de participação pode motivar um envolvimento cívico futuro nas comunidades, pois ainda "[...] poucas são, de fato, as experiências de gestão municipal que assumem uma radicalidade democrática na gestão da coisa pública, assim como ampliam concretamente o potencial participativo" (JACOBI, 2002, p.444).

É necessário melhorar a engenharia institucional visando corrigir eventuais desvios e trazer o cidadão brasileiro às arenas de decisões políticas, visando o bem comum e não de pequenos grupos. Há uma grande jornada a ser percorrida no estudo da gestão urbana brasileira uma vez que neste início de Século XXI ainda existem muitos equívocos no interior dos órgãos públicos.

Casos, como o de Curitiba, revelam que os diversos órgãos dos poderes executivo e legislativo municipal não se comunicam, falta sinergia institucional (CARVALHO JÚNIOR, 2007, p. 216). Dentro deste cenário o cidadão fica descrente e desmotivado a participar da vida pública local, ou seja, um cenário insustentável.

Melhorar as instituições, em especial as públicas, é uma necessidade apontada pelo texto da Agenda 21 na busca de uma sociedade mais harmônica com o meio natural que a cerca:

[...] é necessário fortalecer as abordagens multidisciplinares existentes e desenvolver mais estudos interdisciplinares entre a comunidade científica e tecnológica e os responsáveis por decisões e, com a ajuda do público em geral, proporcionar liderança e conhecimentos técnico-científicos práticos ao conceito de desenvolvimento sustentável (CNUMAD, 2001, p. 218).

Deste modo, as reflexões e sugestões aqui apresentadas são no sentido de uma possível solução ao fortalecimento da intervenção comunitária na política urbana local, a qual está eivada de utopias e equívocos, mantendo as cidades brasileiras numa realidade caótica e insustentável. Cabe à reflexão procurar lançar a luz do conhecimento visando a melhoria contínua das comunidades envolvidas, principalmente em tempos de alarde de tecnologias de bens de consumo, e silêncio a respeito de novas tecnologias sociais.

\section{REFERÊNCIAS}

ALMEIDA, Carla; TATAGIBA, Luciana. Os conselhos gestores sob o crivo da política: balanços e perspectivas. Serv. Soc. Soc., São Paulo, n. 109, p. 68-92, jan. /mar. 2012.

AVRITZER, L., PEREIRA, M. de Lourdes Dolabela. Democracia, Participação e Instituição Hibridas. In: Teoria e Sociedade. Belo Horizonte: UFMG. n. especial, mar. 2005.

BARRETO, Pereira. Soluções positivas da política brasileira. São Paulo: Escala, 2007.

BOBBIO, Norberto; MATTEUCI, Nicolas; PASQUINO, Gianfranco. Dicionário de política. vol. II. 13. ed. Brasília: UNB, 2010. 
BONAVIDES, Paulo. Ciência política. 10. ed. São Paulo: Malheiros, 1994.

BRASIL. Lei Federal n. 10.257 (2001). Lei da Política Urbana (Plano Diretor). Disponível em $<$ www. planalto.gov.br>. Acesso em: 10/01/2015.

Constituição (1988). Constituição da República Federativa do Brasil. Disponível em <www.planalto.gov.br>. Acesso em: 05/08/2016.

Lei Federal n. 4.737 (1965). Código Eleitoral. Disponível em <www.planalto.gov.br>. Acesso em: 05/08/2016.

BRESSER PEREIRA. A reforma do Estado dos anos 90: A lógica e mecanismos de controle. In Lua Nova, n. 45. São Paulo: ANPOCS, 1998, ps. 49-95.

CAGGIANO, Monica Herman S. O cidadão-eleitor: O voto e o papel que desempenha no quadro brasileiro. In MARTINS, Ives Gandra da Silva. As vertentes do direito constitucional contemporâneo. Rio de Janeiro: América Jurídica, 2002, p. 535-557.

CARVALHO JÚNIOR, Moacir Ribeiro de. O interesse popular na gestão dos recursos hídricos sob a ótica do desenvolvimento sustentável: O caso da Bacia do Rio Belém em Curitiba/PR. 2007. 268 f. Dissertação (mestrado) Programa de Pós-Graduação em Gestão Urbana (PPGTU), Pontifícia Universidade Católica do Paraná, Curitiba.

CERQUeIRA, Thales Tácito; CERQUeIRA, Camila Medeiros de Albuquerque Pontes Luz de Pádua. Direito eleitoral esquematizado. São Paulo: Saraiva, 2011.

CIDADES - Ministério das Cidades. O Estatuto da Cidade: Comentado. São Paulo: Ministério das Cidades: Aliança das cidades, 2010.

Plano diretor participativo: guia para elaboração pelos municípios e cidadãos. 2. ed. Brasília: CONFEA, 2005.

CNUMAD, Conferência das Nações Unidas sobre Meio Ambiente e Desenvolvimento (1992: Rio de Janeiro). Agenda 21. Curitiba: IPARDES, 2001.

CONCITIBA, Conselho da Cidade de Curitiba. Resolução n. 25, de $1^{\circ}$ de abril de 2013. Aprova o Regimento da 5a Conferência Municipal da Cidade de Curitiba - 5a COMCURITIBA. Disponível em: <http://concitiba.ippuc.org.br/>. Acesso em 18/08/2016.

ESPING-ANDERSEN, Gosta. O futuro do WelfareState na nova ordem mundial. In Lua Nova, n. 35. São Paulo: ANPOCS, 1995, ps. 73-111.

FAORO, Raymundo. Os donos do poder: formação do patronato brasileiro. 5. ed. São Paulo: Globo, 2012.

FERREIRA, Pinto. Comentários à Constituição brasileira. São Paulo: Saraiva, 1989.

FREY, Klaus. Governança interativa: uma concepção para compreender a gestão pública participativa? In Política \& Sociedade. Revista de Sociologia Política, v. 01, n. 05. Florianópolis: UFSC: Cidade Futura, 2004, p. 117-136. 
GOHN, Maria da Glória. Empoderamento e participação da comunidade em políticas sociais. Saúde e Sociedade v.13, n.2, p.20-31, maio-ago 2004.

HOLANDA, Sergio Buarque de. Raízes do Brasil. 26 ed. São Paulo: Companhia das Letras, 1995.

IASI, Mauro Luis. A rebelião, a cidade e a consciência. In MARICATO, Ermínia ... [et al.]. São Paulo: Boitempo: Carta Maior, 2013, p. 41-46.

JACOBI, Pedro. Políticas sociais locais e os desafios da participação citadina. Ciência e Saúde coletiva, 7(3), 443-454, 2002.

KLEBA, Maria Elisabeth; COMERLATTO, Dunia; FROZZA, Kenia Munaretti. Instrumentos e mecanismos de gestão: contribuições ao processo decisório em conselhos de políticas públicas. Rev. Adm. Pública, Rio de Janeiro, v. 49, n. 4, p. 1059-1079, Aug. 2015. Disponível em <http://www.scielo.br>. Acesso em 15/06/2016.

LÍGIA, Melo. Direito à moradia no Brasil: política urbana e acesso por meio da regularização fundiária. Belo Horizonte: Fórum, 2010.

MARICATO, Ermínia. Brasil, cidades: Alternativas para a crise urbana. 7. ed. Petrópolis/RJ: Vozes, 2013.

MARTINE, George. População, meio ambiente e desenvolvimento: o cenário global e nacional. In MARTINE, G. (org.). População, meio ambiente e desenvolvimento: verdades e contradições. 2. ed. Campinas: Unicamp, 1996.

MARTINS, Ives Gandra da Silva. As vertentes do direito constitucional contemporâneo. Rio de Janeiro: América Jurídica, 2002.

MINGHELLI, Marcelo. Orçamento participativo: uma leitura jurídico-política. Canoas: ULBRA, 2005.

MEIRELLES, Hely Lopes. Direito administrativo brasileiro.42. ed. São Paulo: Malheiros, 2016.

MMA/BRASIL. Ministério do Meio Ambiente/Secretaria de Políticas para o Desenvolvimento Sustentável. A Agenda 21, o semiárido e a luta contra a desertificação. Caderno de debate Agenda 21 e sustentabilidade - n. 06. Brasília: MMA, 2004.

MOISÉS, José Álvaro. Cidadania e participação: ensaio sobre o plebiscito, o referendo e a iniciativa popular legislativa na Nova Constituição. 2. ed. São Paulo: Marco Zero, 2002.

NAÇOES UNIDAS. Comitê de Direitos Humanos. CCPR General Comment No. 25: Article 25 (Participation in Public Affairs and the Right to Vote), The Right to Participate in Public Affairs, Voting Rights and the Right of Equal Access to Public Service. Disponivel em http://www.refworld.org/docid/453883fc22.html, acesso em 19.set.16.

PEREIRA, Erick Wilson. Direito eleitoral: interpretação e aplicação das normas constitucionaiseleitorais. São Paulo: Saraiva 2010. 
PEREIRA, Rodolfo Viana. Direito Constitucional Democrático: Controle e participação como elementos fundantes e garantidores da constitucionalidade. Rio de Janeiro: Lumen Juris, 2008.

RATTNER, Henrique. Reflexões sobre o futuro das cidades. Disponível em: <http://www.abdl.org.br> Acesso em 12/07/2005.

REZENDE, Denis Alcides; CASTOR, Belmiro Valverde Jobim. Planejamento estratégico municipal: Empreendedorismo participativo nas cidades, prefeituras e organizações públicas. Rio de Janeiro: Brasport, 2005.

SANTOS, José Vicente Tavares. Novas questões sociais mundiais, projetos sociais e culturais e a planificação emancipatória. Revista Humanas, v. 24, n 1/2, p. 163-185. Porto Alegre: UFRGS, 2001.

SAULE JÚNIOR. Nelson. Novas perspectivas do direito urbanístico brasileiro. Ordenamento constitucional da política urbana. Aplicação e eficácia do plano diretor. Porto Alegre: Sergio Antonio Fabris, 1997.

SILVA, José Afonso. Curso de direito constitucional positivo. 39. ed. São Paulo: Malheiros, 2016.

TATAGIBA, L. (2002). Os Conselhos Gestores e a Democratização das Políticas Públicas no Brasil. IN: DAGNINO, E. (org.) Sociedade Civil e Espaços Públicos no Brasil. São Paulo: Paz e Terra.

TEMER, Michel. Elementos de direito constitucional. 16ạ edição. São Paulo: Malheiros, 2000.

VILLAÇA, Flávio. As ilusões do Plano Diretor. São Paulo, 2005. Disponível em:<http://www.usp.br>. Acesso em 05/08/2016.

VELLOSO, Carlos Mário da Silva; AGRA, Walber de Moura. Elementos de direito eleitoral. 2. ed. São Paulo: Saraiva, 2010.

Trabalho enviado em 25 de setembro de 2016.

Aceito em 06 de janeiro de 2017. 